\title{
Real-time Monitoring of Suspended Particulate Matter in Indoor Air: Validation and Application of a Light-scattering Sensor
}

\author{
Anna Susz ${ }^{*}$, Pascal Pratte, Catherine Goujon-Ginglinger \\ Philip Morris Products S.A., CH-2000 Neuchâtel, Switzerland
}

\begin{abstract}
Since the 1950s, awareness of the impact of air pollution on human health has been growing. Of the many recognized air pollutants, suspended particulate matter has received the most attention, as both $\mathrm{PM}_{2.5}$ and $\mathrm{PM}_{10}$ can affect humans upon inhalation. Consequently, PM monitoring is critical to linking indoor pollution and exposure, and a validated measuring instrument is essential. Portable monitors, which track temporal changes in the aerosol mass concentration in real time, are a faster alternative to offline gravimetric techniques, which provide only averaged values. Hence, this study evaluated the performance of the DustTrak DRX aerosol monitor in assessing indoor air quality and validated its ability to measure complex aerosols. Three DustTrak units were used to measure different aerosols, e.g., ambient air, polystyrene latex (PSL) spheres, and environmental tobacco smoke (ETS), and the results were compared to those obtained with the standard gravimetric method. Notably, the bias of the DustTrak relative to the gravimetric method for ETS measurements ranged from $2 \%$ to $15 \%$ when a photometric calibration factor (PCF) of 0.38 was applied. Additionally, the working range of the tested units was established, and the limits of detection and quantification were found to be 5 and $15 \mu \mathrm{g} \mathrm{m}^{-3}$, respectively. Finally, in order to serve as an alternative to the gravimetric method, these instruments must be accredited for PM measurement in accordance with standards such as ISO 17025.
\end{abstract}

Keywords: DustTrak DRX; $\mathrm{PM}_{2.5} ; \mathrm{PM}_{10}$; Suspended particulate matter; Environmental tobacco smoke (ETS).

\section{INTRODUCTION}

The demographic expansion and advent of mass production at the beginning of the last century led to a steep rise in anthropogenic activities, resulting in a massive increase in air pollution (Friket, 1931; Brunekreef, 2010). Over the last 30 years, this has proved to be a matter of the highest concern to health authorities around the globe, with particular attention paid to the increase in suspended particulate matter (PM) mass concentrations associated with sources such as mineral dust, cigarette smoke, biomass burning, and combustion engine emissions, to cite a few (Ott and Siegmann, 2006; WHO, 2006; Methner et al., 2010; Buonanno et al., 2011; McNamara et al., 2011; Rakowska et al., 2014). In particular, the burden of air pollution is attributed more to $\mathrm{PM}_{2.5}$ mass concentration (particulates smaller than $2.5 \mu \mathrm{m}$ in diameter) than to the coarse $\mathrm{PM}_{10}$ (particulates smaller than $10 \mu \mathrm{m}$ in diameter) (Pope and Dockery, 2006; McGuinn et al., 2016). A wide range of health issues can appear when people are exposed to PM (; WHO, 2006; Kloog et al., 2013;

\footnotetext{
* Corresponding author.

Tel.: +41 (58) 242 2460, Fax: +41 (58) 2422811

E-mail address: annamagdalena.susz@ pmi.com
}

WHO, 2013; Sajjadi et al., 2017; Wong-Parodi et al., 2018). Therefore, different regulatory bodies have defined limits for daily/yearly average ambient $\mathrm{PM}_{2.5}$ concentrations. For instance, the yearly $\mathrm{PM}_{2.5}$ average exposure limits set by the European authorities and World Health Organization (WHO) are 25 and $10 \mu \mathrm{g} \mathrm{m}^{-3}$, respectively (EU, 2008; EEA, 2017). However, even short-term exposure to low levels of PM can lead to negative impact on health (Zhao et al., 2020). With every $10 \mu \mathrm{g} \mathrm{m}^{-3}$ increase in $\mathrm{PM}_{2.5}$ exposure there can be a $2.8 \%$ increase in PM-related mortality (Kloog et al., 2013). Physiologically, when an aerosol is inhaled, the suspended $\mathrm{PM}_{2.5}$ reaches the alveolar region and is deposited locally (Jakobsson et al., 2016; Kuuluvainen et al., 2016; Rissler et al., 2017). If the deposited PM is composed of water-insoluble elements, solid-state particles may be transported into the blood stream, thus promoting risk-related diseases such as cardiopulmonary disorders and/or cancer (Brook et al., 2010; Silva et al., 2013; Segersson et al., 2017). For this reason, accurate measurement of $\mathrm{PM}_{2.5}$ concentrations is essential for estimating dose exposure in different environments and ensuring that the outdoor and indoor air quality is acceptable against established standards, thereby contributing to a good quality of life.

A number of techniques are available for measuring $\mathrm{PM}_{2.5}$ levels, each having their own advantages and disadvantages. The most commonly used technique is the gravimetric 
method, in which membrane Teflon filters are used to collect PM. This procedure is recognized by regulatory bodies (U.S. EPA, 1997; Hinds, 1999; ISO, 2001, 2003; Wang et al., 2016), as it allows direct mass reading for calculating PM time-averaged mass concentrations. However, data generation is labor-intensive because of the need for conditioning the filters before and after collection, and the approach fails to provide high space-time resolution. Unfortunately, gravimetric methods are offline techniques for which data evaluation and interpretation are generally performed days or weeks after the aerosols are collected (U.S. EPA, 1997; Chung et al., 2001). Such methods have been found to be inappropriate for many applications where rapid measurement is required, such as field campaigns (Pui, 1996; McMurry, 2000). Finally, when aerosol PM is trapped on the filters, the chemical compounds may undergo chemical reactions and/or evaporate during the transport and conditioning of samples prior to measurement (Huang et al., 2013; Wang et al., 2016).

Since the 1970s (McMullen et al., 1970; Brasser et al., 1978; Muylle et al., 1978), alternative solutions have been developed to measure real-time PM mass concentration. For instance, previous studies have evaluated various techniques for measuring suspended PM using tapered element oscillating microbalances (Allen et al., 1997), nephelometers, optical particle counters, and aerodynamic particle spectrometers (Pui, 1996; Hinds, 1999; Chung et al., 2001; Kingham et al., 2006; Ott and Siegmann, 2006; Wallace et al., 2011; Amaral et al., 2015). Among these analytical tools, one method is based on light scattering and has the advantages of being generally portable (Pui, 1996; Manikonda et al., 2016; Sousan et al., 2016; Zhang et al., 2018), and capable of monitoring $\mathrm{PM}_{2.5}$ concentrations in real time. Additionally, the time resolution for light-scattering instruments is typically in the order of magnitude of a minute or even a few seconds (McMurry, 2000; Ramachandran et al., 2000; Zhang et al., 2018). This time resolution allows monitoring of peak concentration events, which can be correlated to health effects data (Chung et al., 2001; Brook et al., 2010; Brunekreef, 2010; McGuinn et al., 2017). Often, light-scattering instruments consist of relatively small, portable, battery-operated devices, which are calibrated for a wide range of concentrations and environmental temperatures $\left(0-200 \mathrm{mg} \mathrm{m}^{-3}\right.$ and up to $\left.60^{\circ} \mathrm{C}\right)$ (Sousan et al., 2016; van Dinther et al., 2019). In this category of online monitoring instruments there are three distinguished groups: Consumer Air Quality Monitors (CAMs), which are very inexpensive $(\sim 300)$ and small like Foobot, SidePak or AirVisual (Sousan et al., 2017; Singer and Delp, 2018; Manibusan and Mainelis, 2020); laboratory- or regulatorygrade monitors, which are more expensive $(\sim 50,000)$ and more precise but not portable like Grimm Environmental Dust Monitor (Grimm and Eatough, 2009; Mehadi et al., 2020); and the last intermediate group like the DustTrak DRX aerosol monitor $(\sim 10,000)$ as a lower-cost alternative to the laboratory-grade sensors (Wang et al., 2009).

However, for indoor or outdoor air quality applications, no commonly accepted methodology exists today for determining the limit of detection (LOD) or limit of quantification (LOQ) for continuous light-scattering instruments (Wallace et al., 2011). The main challenge is to use appropriate scattering techniques while applying correct calibration factors, which strongly depend on the physicochemical properties of the test aerosols (Kingham et al., 2006; Hinds, 1999; Pui, 1996; Wallace et al., 2011). Although these monitors can be used for a range of aerosol compositions, concentrations, and sizes, they do not allow differentiation between solid and liquid suspended PM. It is equally important that the physical state and shape of the suspended PM may affect the aerosol optical properties, which can lead to incorrect aerosol size classification and mass determination (Hinds, 1999). Consequently, the choice of a robust instrumentcalibrated as fit-for-purpose and validated-is essential to accurately evaluate dose exposure in humans. Amongst these portable instruments, one stands out as having all the advantages such as portability, ease of use, possibility of online operation, coverage of a wide range of concentrations, and easy adaptation to different types of aerosol matrices (by changing the photometric factor). This instrument is the portable aerosol monitor from TSI Inc. (Shoreview, Minnesota, USA), commercialized under the brand DustTrak DRX.

The manufacturer's specifications indicate that this instrument was developed to estimate size-segregated aerosol mass concentrations (i.e., $\mathrm{PM}_{10}, \mathrm{PM}_{4}, \mathrm{PM}_{2.5}$, and $\mathrm{PM}_{1}$ ) over a wide concentration range $\left(0.001-150 \mathrm{mg} \mathrm{m}^{-3}\right.$ ) (Wang et $a l ., 2009)$. The DustTrak DRX was originally designed and calibrated to monitor mineral dust concentrations in industrial environments and was not intended for ambient aerosol tracking (Kingham et al., 2006; McNamara et al., 2011). From the literature, it was concluded that, when the mineral dust calibration factors are applied to ambient indoor and outdoor aerosols, results of aerosol mass concentration are generally overestimated by a factor of 2.64 relative to gravimetric measurements (Wang et al., 2009; Wallace et al., 2011; TSI Inc., 2013). This is mainly due to the fact that mineral dust and ambient aerosols are characterized by diverse physicochemical properties, which translate into differences in refractive indexes, composition, suspended PM shapes and physical states, density, and morphology (Nousiainen, 2009; Di Biagio et al., 2019). Moreover, this work highlights the importance for selection of an appropriate calibration factor for DustTrak DRX or similar laseroperated aerosol mass analyzers, not only in the evaluation of environmental tobacco smoke (ETS), but also when assessing other environmental aerosols, e.g., those of e-vapor products (EVPs) or electrically heated tobacco products (EHTPs). The application of an erroneous photometric calibration factor (PCF) might lead to large discrepancies in the concentrations reported for suspended particulate matter (Melstrom et al., 2017; Protano et al., 2018; Volesky et al., 2018; Protano et al., 2020). Tests of the performance of aerosol monitors in different conditions are important because they ensure the accuracy of the DustTrak DRX mass aerosol concentration measurements, on the basis of which the indoor air quality levels for exposure to different harmful substances can be precisely established.

The linearity, precision, selectivity, bias, and working range of DustTrak DRX were assessed simultaneously through a validation process on three units, with the goal of evaluating the suitability of the equipment for air quality 
measurement with main focus on ETS exposure. Additionally, the Swiss Accreditation Services were requested to audit the validation process in accordance with ISO 17025 standards (ISO, 1999, 2017).

\section{METHODS}

\section{General Approach}

The calibration frequency of DustTrak DRX monitors are made once per year by the supplier, TSI Inc. Calibration is done using Emery oil and then nominally adjusted to the respirable mass of standard A1 test dust with a photometric calibration factor of 1 . After calibration, instruments were shipped from the calibration facility in the UK to the test facility in Switzerland. The travel distance corresponded to approximately $1000 \mathrm{~km}$, and vibrations during the transport may have led to misalignment of the instrument optics, potentially affecting their performance (Rivas et al., 2017).

The three DustTrak DRX aerosol monitors from TSI Inc. were selected from among similar types of sensors because of their simplicity of use, portability, and convenience for field campaigns. These instruments use a 655-nm laser to illuminate an aerosol sample, for which the scattered light is measured on a perpendicular beam by a photodetector (Wang et al., 2009). The photometric signal measured by DustTrak is stronger when the particle diameter is close to the laser wavelength $(655 \mathrm{~nm})$. Therefore, a photometer is very sensitive when considering fine suspended PM, although it underestimates the masses of small and large particles because of Mie scattering limitations (Wang et al., 2009). This is based on the fact that the scattered light is a function of the total volume of suspended PM, associated refractive index, and PM shape and form (Wallace et al., 2011). The total flow rate of DustTrak DRX was set to $3 \mathrm{~L} \mathrm{~min}^{-1}$, of which $2 \mathrm{~L} \mathrm{~min}^{-1}$ allowed the aerosol sample to be conveyed into the measurement chamber, while the remaining $1 \mathrm{~L} \mathrm{~min}^{-1}$ was filtered and used as sheath air flow (TSI Inc., 2017). The DustTrak DRX aerosol monitor has two calibration factors: a photometric calibration factor and size calibration factor (SCF). The PCF accounts for the difference in photometric response between A1 test dust and the aerosols under measurement, while the SCF accounts for aerodynamic size differences (TSI Inc., 2017).

The relationship between the gravimetric and DRX measurements obtained for A1 dust is shown as the PCF in Eq. (1) (Wang et al., 2009).

$$
P C F=\frac{\text { Gravimetric } \mathrm{PM}_{2.5} \text { mass concentration }}{\mathrm{DRX} \mathrm{PM}_{2.5} \text { mass concentration for } \mathrm{A}_{1} \text { dust }}
$$

PCF of 0.38 was used in the current work. TSI Inc. recommends a $\mathrm{PCF}$ of 0.38 when considering ambient aerosols (TSI Inc., 2013, 2017). The difference between $\mathrm{PCF}=0.38$ and $\mathrm{PCF}=1$ is attributed to the differences in physicochemical nature between the ambient suspended PM and Arizona test dust. To confirm that the ETS aerosol matrix could be quantified adequately using the ambient aerosol PCF (0.38), the performance of the DustTrak DRX aerosol monitor was assessed against that of a gravimetric method using Marlboro Gold cigarettes to generate ETS in an environmentally controlled room (described in next sections).

The concentration range of the DustTrak DRX (softwaredetermined) is between 0.001 and $150 \mathrm{mg} \mathrm{m}^{-3}$, and the size ranged from 0.1 to $15 \mu \mathrm{m}$ (TSI Inc., 2017). The scattering intensities of individual particles are used to group particles into five broad-size bins - typically $\mathrm{PM}_{1}, \mathrm{PM}_{2.5}, \mathrm{PM}_{4}, \mathrm{PM}_{10}$, and $\mathrm{PM}_{\text {Total }}$ (Wang et al., 2009).

For verification purposes, the Swiss Federal Institute of Metrology (METAS; Wabern, Switzerland) was mandated to evaluate the mass concentration linearity of the instruments. The curve responses were compared to that stated on the calibration certificates issued by TSI Inc. to identify any potential bias. Moreover, the selectivity of the instruments was evaluated at the Philip Morris International (PMI) R\&D test facility by checking whether the associated size-segregated channels reacted adequately to calibrated National Institute of Standards and Technology (NIST)-traceable polystyrene sphere latex (PSL) particles. In the last step, the performance of the instruments was tested on ambient air from a standard laboratory environment as well as environmental tobacco smoke. The main purpose of this assessment was to identify the appropriate calibration factors to be set so that the instruments could provide accurate and precise data for ETS or similar matrix of aerosol.

\section{PM2.5 Mass Concentration Linearity Response}

METAS performed a linearity mass concentration response test, including repeatability (repetition within a day) and intermediate precision (repetition between days) tests, using different mass loadings of Emery oil (density: $0.817 \mathrm{~kg} \mathrm{~m}^{-3}$; Synfluid ${ }^{\circ}$ PAO 4 cSt; Chevron Phillips Chemical Company LP; The Woodlands, Texas, USA). The first reason for which this particular aerosol was chosen is its low volatility, which prevents droplets from evaporating significantly during the course of the experiment. The second reason was to recreate the same conditions as those used for calibration of the aerosol monitors by TSI Inc. The last reason was that Emery oil has been shown to produce a linear photometric signal proportional to A1 test dust (ISO 12103-1; Arizona Road Dust) mass concentration (Wang et al., 2009).

For this part of the study PCF = 1 was used for comparison with the supplier's linearity mass concentration response. Emery oil droplets were nebulized in isopropanol (v/v $0.8 \%$ ) at a flow rate of $8 \mathrm{~mL} \mathrm{~h}^{-1}$ using a mass flow controller (M50SLPM-D; NATEC Sensors; and 5V SN 86387; Bronkhorst High-Tech B.V., Netherlands) with dry pressurized air using a Meinhard nebulizer (Colorado, USA) coupled to a cyclonic spraying chamber at a pressure of 2.5 bar. Aerosol generation was adjusted and controlled by monitoring droplet size and concentration with a Scanning Mobility Particle Sizer (SMPS; DMA 3080, CPC 3775, and Software AIM version 9.0.0.0; TSI Inc.) and 47-mm filters (DTX40HI20W; Pall Life, Portsmouth, Hampshire, UK). The reference filter was used to control the Emery oil mass loadings and weighed using an ultra-micro balance (UMT 5; Mettler Toledo, Columbus, Ohio, USA) before and after loading.

From the SMPS measurements, the aerosols were 
characterized on the basis of a mass-based mean mobility diameter ranging from 441 to $445 \mathrm{~nm}$, with a geometric standard deviation of $1.41 \pm 0.01$. Five different aerosol mass concentrations were generated $(0.02,0.2,0.5,1.0$, and $3.0 \mathrm{mg} \mathrm{m}^{-3}$ ) and verified with gravimetric method using different times for collection of Emery oil on the filter pad. The collection was repeated over five different testing days. This resulted in five different mass loadings for each testing day. Next, the mass loadings were converted into associated average mass concentrations and compared with the mass concentration measured by the three DustTrak units by recording data with 1-min logging interval (Table 1).

Efficiency was expressed as the ratio between the aerosol mass concentration measured by the DustTrak DRX unit using $\mathrm{PCF}=1$ and the theoretical mass concentration of Emery oil confirmed by the gravimetric method according to Eq. (2):

$$
\text { Efficiency }=\frac{\gamma_{D T}}{\gamma_{\text {Reference }}}
$$

where $\gamma_{D T}$ is mass concentration obtained by the DustTrak unit and $\gamma_{\text {Reference }}$ is mass obtained by gravimetric method.

In order to estimate exposure levels to fine suspended PM, the within-day and between-day variability of $\mathrm{PM}_{2.5}$ had to be maintained under control. For this purpose, the mass concentration response curve of Emery oil, which served as the surrogate aerosol, was correlated to gravimetric data. The acceptance criteria were defined on the basis of any bias with the supplier's specifications, together with inter-unit variability. In the present work, it was decided to use $10 \%$ as the acceptance criterion for assessing whether an instrument demonstrated acceptable performance. This threshold value was defined as the exclusion criterion for not considering out-of-specification units, thereby avoid misleading doses of exposure response.

The PCF was set to unity with the aim of comparing the METAS data to those shown on TSI Inc. calibration certificates. Ambient aerosol matrix calibration $(\mathrm{PCF}=0.38)$ was not used in this case because the optical properties of Emery oil (refractive index $=1.4645$ ) are very similar to those of mineral dust (refractive index $=1.54$ ) (Wang et al., 2009).

\section{Size Selectivity for the PM ${ }_{2.5}$ Channel with PSL Aerosols}

The selectivity of the size channels in the DustTrak DRX aerosol monitors was evaluated using commercially available NIST-traceable PSL (Thermo Fisher Scientific, Waltham, Massachusetts, USA). PSL particles with $2.5-\mu \mathrm{m}$ diameters were prepared by diluting the standard solution in ultra-pure water (LC/MS Grade) in a ratio of 1:300 (v/v). The solution was atomized using a Constant Output Atomizer (COA, Model 3076; TSI Inc.) at an inlet pressure of $2 \mathrm{Ba}$. The generated aerosols were transported through black tubing, enabled to reduce electrostatic losses, to a diffusion dryer (Model 3062; TSI Inc.) filled with activated silica gel particles in order to remove the gas-phase and water layers around the PSL particles. The dried PSL aerosols were then directly transported and measured using the DustTrak DRX units.

\section{$L O D$ and $L O Q$}

$L O D$ is defined as the lowest possible concentration that can be detected, equivalent to a signal-to-noise ratio smaller than a factor of 3. To obtain the LOD of individual DustTrak units, the sensors were positioned next to each other to ensure that all three instruments sampled the same aerosol concentrations. The lowest concentration measured should be above the resolution limit of the instrument defined by the supplier (i.e., $0.001 \mathrm{mg} \mathrm{m}^{-3}$ ). The background level of laboratory air was measured for $60 \mathrm{~min}$ at the beginning of each testing day. This experiment was repeated over ten different testing days. The method LOD was established on the basis of the average concentrations measured for background room air by each of the three DustTrak units on each of the experimental days. Values more than $7 \mu \mathrm{g} \mathrm{m}^{-3}$ were suspected to be outliers and were not taken into consideration for calculating the standard deviation (SD). Subsequently, the LOD was calculated by multiplying the SD by a factor of 3 and LOQ by a factor of 10 using the same SD.

\section{Bias}

The term bias can be defined as a difference between an instrument reading and the "true" reading or reading provided by the reference instrument or method. It can be calculated using following Eq. (3):

$\operatorname{Bias}(\%)=\frac{A_{1}-A_{2}}{A_{2}} \times 100 \%$

where $A_{1}$ is the instrument reading during validation and $A_{2}$ is the reference reading ("true") value.

The bias for each instrument was calculated individually in comparison to the gravimetric method, which was taken in this case as a "true" value.

In case of comparison instrument for linearity check in terms of mass concentration, the reference instrument value was taken from the reading of DustTrak DRX Unit 1.

Bias was calculated for Emery oil measurements in linearity response experiments and later for comparison of ETS data obtained by three DustTrak DRX units.

\section{Environmentally Controlled Room Settings and Measurement of ETS Mass Concentration}

A leak-tight, ventilated, environmentally controlled room (24.1 $\mathrm{m}^{2}, 72.3 \mathrm{~m}^{3}$ ) located in PMI R\&D (Neuchâtel, Switzerland) was used for quantifying pollutants in air (Mottier et al., 2016; Gomez Lueso et al., 2018) and assessing the impact of environmental aerosols like ETS on indoor air quality (Schaller et al., 2016; Mitova et al., 2016; Mottier et al., 2016; Gomez Lueso et al., 2018). The room was equipped with a ventilation system that supplied fresh filtered air at a rate of $121 \mathrm{~m}^{3} \mathrm{~h}^{-1}$, corresponding to 1.7 air changes per hour (ECS, 2006; Mitova et al., 2016) and maintained at $23 \pm 3^{\circ} \mathrm{C}$. The air supply was filtered through activated charcoal to remove volatile organic compounds; 
three filters trapped suspended PM, while two electric fans were used to mix and distribute the indoor air. After each test session, the room was ventilated with a high volume of fresh air supplied overnight.

Prior to evaluating the performance of the DustTrak, the three units were simultaneously operated for $1 \mathrm{~h}$ on ten testing days to measure the background concentration of air in the room, on the basis of which the LOD of the methodology was established. Four out of ten background sessions were conducted at the same days as the exposure sessions with ETS. The design of experiments in the controlled room included additional background sessions without any exposure to gather more representative results for the ambient aerosol. ETS generation and measurements were performed over four 1-h sessions, where three test items were used each hour; the three test items were treated as one replicate, giving a total of 12 cigarettes smoked per testing day and in total 48 cigarettes for all exposure experiments. Data for ETS mass concentration were averaged over $1 \mathrm{~h}$ with recording data frequency of $1 \mathrm{~min}$. The ETS measurements were performed over four consecutive days using a programmable single syringe pump (PSSP SE; Burghart Messtechnik GmbH, Wedel, Germany); the Health Canada smoking regimen was applied for these measurements (Mottier et al., 2016). The cigarette smoke was released directly into the room and the mass concentration response was monitored simultaneously by the three DustTrak units, and collected in a gravimetric collector for respirable suspended particles (RSP) (U.S. EPA, 1997; EU, 2008; WHO, 2013) positioned side by side at approximately $10 \mathrm{~cm}$ from the axis of smoke generation. The results obtained by the DustTrak tests were compared with those of the accredited reference gravimetric method (STS 0045; Swiss Accreditation Service, Bern, Switzerland). This step was necessary to evaluate whether the ambient PCF of 0.38 was appropriate for monitoring the ETS concentration.

\section{PM Determination Using Gravimetric Method}

Operationally, this reference method measures RSP using cyclones as a pre-separator and subsequently selectively collecting the $\mathrm{PM}_{4}$ on filters. For this purpose, aerosols were sampled at the inlet of the cyclone $(37 \mathrm{~mm}$ with $4-\mu \mathrm{m}$ cutoff point; Aluminum Respirable Dust Cyclone, Cat. No. 22501-02; SKC, Inc., Pennsylvania, USA) at a volumetric flow rate of $2.5 \mathrm{~L} \mathrm{~min}^{-1}$. The aerosols entered the cyclone, while inertial forces precipitated suspended PM greater than or equal to $4 \mu \mathrm{m}$ in diameter into a dedicated collector. The residual suspended PM was drawn into a cassette housing containing a polytetrafluoroethylene (PTFE) membrane filter (37-mm diameter and $1-\mu \mathrm{m}$ pore size on polypropylene support; SKC, Inc.), which trapped the aerosol. To obtain the average mass concentration, the PTFE membranes were weighed before and after aerosol collection using an ultramicrobalance (readability $= \pm 0.1 \mu \mathrm{g}$; XP2U; Mettler Toledo). To obtain precise values when weighing the PTFE filters, the filters of the cassette housing were conditioned for $12 \mathrm{~h}$ at a relative humidity of $50 \pm 5 \%$ and temperature of $22 \pm$ $2^{\circ} \mathrm{C}$ before and after aerosol collection. During the weighing process, the filters were neutralized by passing them through an antistatic electrode integrated into the microbalance in order to avoid electrostatic bias and ensure correct mass determination.

\section{RESULTS AND DISCUSSION}

\section{PM2.5 Mass Concentration Linearity Response by DustTrak DRX Aerosol Monitors}

Fig. 1 shows the linear response of each of the tested aerosol monitors for five different Emery oil mass concentration loadings.

The average mass concentration of Emery oil ( $\gamma$ DustTrak) measured by the three units is plotted as a function of the average mass concentration determined by the gravimetric method ( $\gamma$ Reference; Fig. 1). The slopes, calculated from the straight lines shown in Fig. 1, ranged from 2.59 to 3.03, with $\mathrm{R}^{2}$ values $\geq 0.9999$, which shows that the DustTrak measurements overestimate Emery oil particle measurements compared to the gravimetric estimations. All tested units were in line with the supplier's specifications; however, there were differences in the slope and intercept of the concentration response among the instruments, which could have affected their performance. The random pattern observed in the residual plot indicated that a linear regression model was appropriate for the data (Fig. S1 in Supplementary Materials). The slopes for DustTrak Units 1 and 3 were within $\pm 3 \%$ agreement, which is better than the $10 \%$ bias reported in the literature (Wallace et al., 2011). In contrast, the slope for DustTrak Unit 2 underestimated the aerosol mass concentration by $12-14 \%$ relative to DustTrak Units 1 and 3. Consequently, DustTrak Unit 2 was rejected and not considered for ISO accreditation. To better understand the behavior of DustTrak Unit 2, its efficiency-including within-day variability for Emery oil loadings_-was plotted against that of $\gamma$ Reference (Fig. 2). This plot showed that the variability of the instrument was relatively high at the lower concentration range (low concentration range for $\gamma$ Reference in Fig. 2). This discrepancy was confirmed by METAS, which observed a between-day variability of $10 \%$ (METAS, 2017).

\section{Size Selectivity for the PM2.5 Channel with PSL Aerosols}

The data displayed in Fig. 3 show that four channels out of five simultaneously measuring PM concentration$P M_{\text {Total }}, P M_{10}, \mathrm{PM}_{4}$, and $P M_{2.5}$ — were activated. In contrast, no response was observed for $P M_{l}$, as expected. This demonstrates that the DustTrak DRX aerosol monitor is sensitive for the selected sizes, especially for the $\mathrm{PM}_{2.5}$ channel. This finding is important from a dosimetry point of view, as $\mathrm{PM}_{2.5}$ is a good indicator for exposure to RSP, which can cause risk-related diseases (Segersson et al., 2017). Particles with sizes larger than $\mathrm{PM}_{2.5}$ were detected only by three size-segregated channels, namely, the $\mathrm{PM}_{4}$, $\mathrm{PM}_{10}$, and $\mathrm{PM}_{\text {Total }}$ channels, and not by the $\mathrm{PM}_{2.5}$ channel.

\section{$L O D$ and $L O Q$}

The average $\mathrm{PM}_{2.5}$ values used for calculating the SDs are reported in Table 1; the outliers are also reported but not taken into account for SD calculations. As shown in Table 1, the outliers were out of the range (average \pm SD). The 


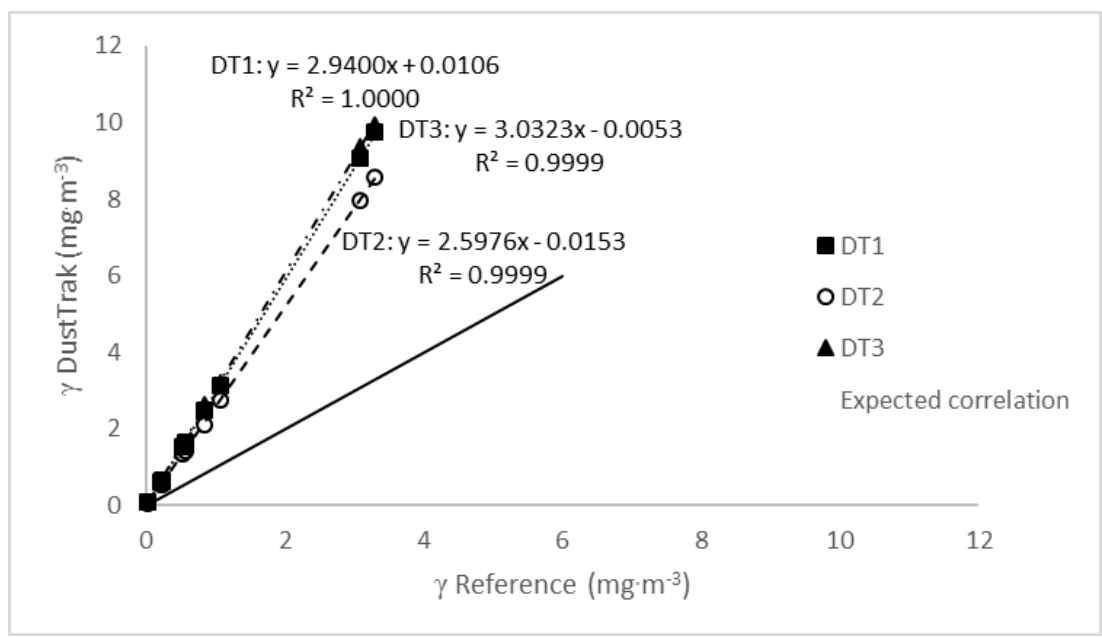

Fig. 1. Linear aerosol mass concentration responses of three DustTrak DRX units (DustTrak Units 1-3 [DT1-DT3]) measured for five calibration points using a reference concentration of Emery oil ( $\gamma$ Reference) and a factory photometric calibration factor $(\mathrm{PCF}=1)$. In the graph an ideal expected correlation between the DustTrak units and the reference is shown with solid line indicating that the DustTrak instruments are overestimating the Emery oil mass concentration. Calibration curves are based on the calibration certificates provided by METAS (Wabern, Switzerland).

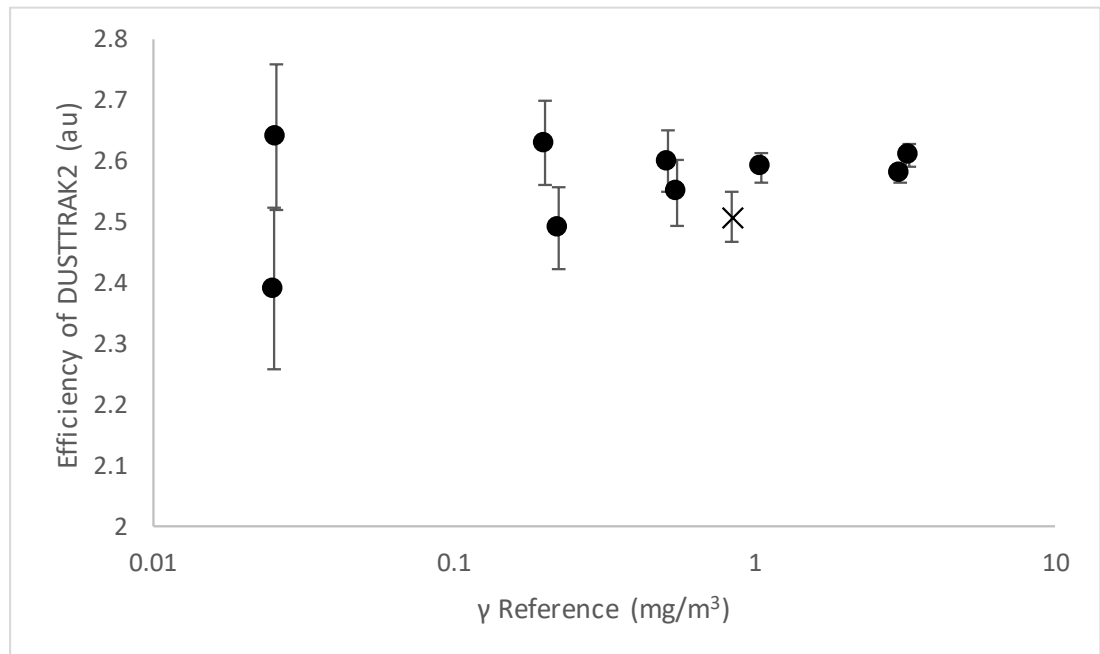

Fig. 2. Efficiency of DustTrak Unit 2 as a function of the aerosol mass concentration of Emery oil ( $\gamma$ Reference). Efficiency is expressed as the ratio between the aerosol mass concentration measured by the DustTrak DRX unit using PCF $=1$ and the theoretical mass concentration of Emery oil confirmed by the gravimetric method. The black cross denotes the average value of inter-day repeatability measurements. Error bars represent standard deviation of the average value of the measured mass concentration for the three replicates per concentration level. Data generated by METAS (Wabern, Switzerland) during recalibration of the DustTrak DRX units with Emery oil.

accepted LOD for all three DustTrak units was found to be $5 \mu \mathrm{g} \mathrm{m}^{-3}$, comparable to the LOD published in the literature (Wallace et al., 2011). Consequently, the LOQ for all three instruments was established at a level of $15 \mu \mathrm{g} \mathrm{m}^{-3}$.

\section{Evaluation of Bias in Comparison to the Reference Gravimetric Method}

Experiments were performed to determine the photometric calibration factor to be applied to DustTrak measurements of ETS (Wallace et al., 2011; TSI Inc., 2013). When the factory default $\mathrm{PCF}$ of 1.0 was used, the $\mathrm{PM}_{2.5}$ measurement from DustTrak Unit 1 overestimated gravimetric measurement by a factor of 1.5 (Day 2 ; Fig. 4). Conversely, when the PCF was set to the ambient calibration factor $(0.38)$, the relative difference between the gravimetric and DustTrak Unit 1 measurements was within 2\% (Days 1, 3, and 4; Fig. 4).

This highlights the importance of proper validation and calibration, because erroneous calibration settings may lead to considerable nonlinear bias. For example, by performing online monitoring with a DustTrak aerosol monitor, Protano et al. (2020) measured $\mathrm{PM}_{2.5}$ median concentrations of $3.4 \mathrm{mg} \mathrm{m}^{-3}$ during smoking of a cigarette, a value several times higher than those reported in the literature for similar experiments (Ruprecht et al., 2017; Forster et al., 2018; 


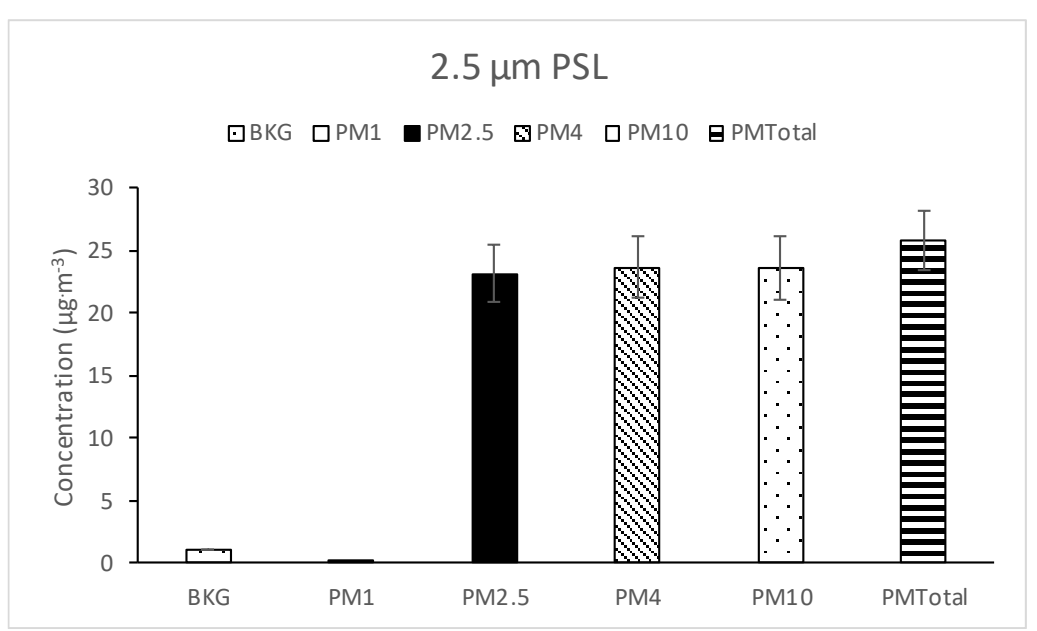

Fig. 3. Real-time aerosol average mass concentration \pm SD measured by DustTrak Unit 1 for NIST-traceable PSL particles with a size of $2.5 \mu \mathrm{m} . B K G$ is the average background for all channels and $P M_{1}, P M_{2.5}, P M_{4}, P M_{10}$ and $P M_{\text {Total }}$ correspond to the particle sizes of $1,2.5,4,10$ and $15 \mu \mathrm{m}$.

Table 1. Loading times of Emery oil on the filter pad for verification of concentration linear response measured by three DustTrak DRX units.

\begin{tabular}{lll}
\hline$\gamma_{\text {nominal }}\left(\mathrm{mg}^{-3}\right)$ & Nominal loading time $(\mathrm{h}: \mathrm{min})$ & Dilution \\
\hline 0.02 & $05: 30$ & $150: 1$ \\
0.2 & $01: 00$ & $15: 1$ \\
0.5 & $00: 30$ & $6: 1$ \\
1.0 & $00: 30$ & $3: 1$ \\
3.0 & $00: 15$ & No dilution \\
\hline
\end{tabular}

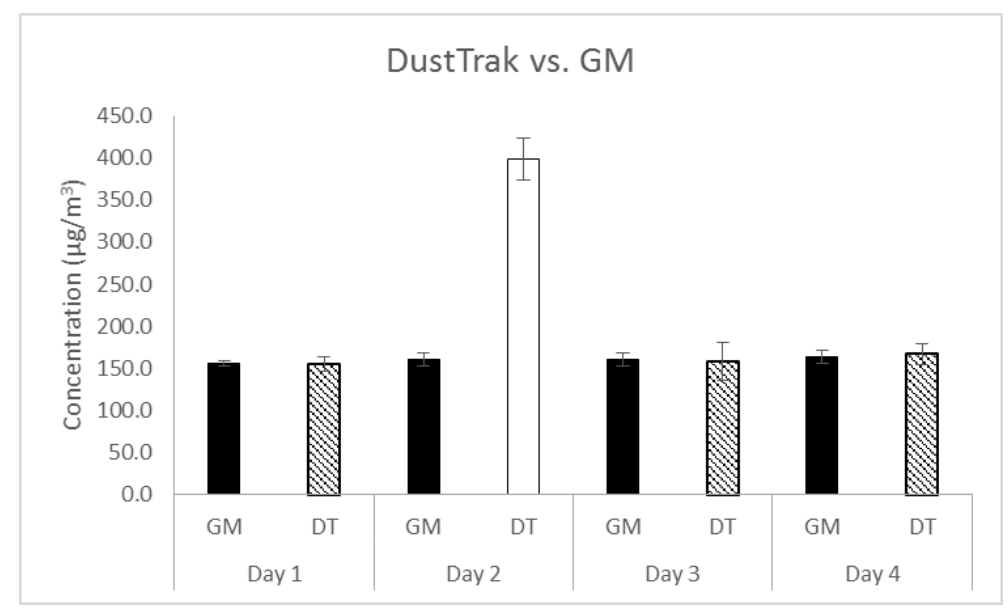

Fig. 4. Comparison of aerosol mass concentration results obtained by the gravimetric method (GM) and DustTrak (DT) Unit 1, with \pm SD error bars. These results were obtained after Marlboro Gold (MLG) cigarettes were smoked in accordance with the Health Canada smoking regimen in an environmentally controlled room with Residential I ventilation conditions $\left(121 \mathrm{~m}^{3} \mathrm{~h}^{-1}\right)$ on four consecutive session days. The DustTrak DRX aerosol monitor measurements for Days 2 and 3 were obtained with different calibration settings. Patterned backslash bars correspond to ambient calibration $(\mathrm{PCF}=0.38)$, and the empty bar corresponds to factory calibration settings $(\mathrm{PCF}=1.0)$.

Meišutovič-Akhtarieva et al., 2019; Mitova et al., 2019). Likewise, extreme values were reported in some studies using laser-operated aerosol mass analyzers to measure PM concentrations during EVP consumption due to use of unadjusted numbers (SidePak) (Melstrom et al., 2017), and calibration with Arizona Road Dust (DustTrak) (Volesky et al., 2018). Similarly, an unsuitable calibration procedure might have been one of the explanations for extreme indoor concentrations of $\mathrm{PM}_{2.5}$ found in experiments with EVPs (Protano et al., 2018), EHTPs and cigarettes (Protano et al., 2020). Currently, PCF values of 0.32 (Soule et al., 2017; Kaufman et al., 2018) and 0.38 (Mitova et al., 2019) are 
considered suitable and applied in laser-operated aerosol mass analyzers for evaluation of environmental aerosols of EVPs and EHTPs. Measurements of the ETS by the DustTrak DRX when using correct photometric calibration (PCF = 0.38 ) is valid only for this type of aerosol; for other type of matrices, it has to be evaluated if it is still appropriate.

With the PCF set to $0.38, \mathrm{PM}_{2.5}$ concentrations from DustTrak Units 2 and 3 were $13 \%$ and $15 \%$ lower than $\mathrm{PM}_{4}$ concentrations obtained using gravimetric method. Moreover, upon statistical analysis of the ETS results, the homogeneity of the variance test for absolute deviation of the mean aerosol mass concentration was found to be nonsignificant, with a p-value of 0.05 (Fig. 5). Therefore, when measuring ETS mass concentrations using a $\mathrm{PCF}=0.38$, an instrument bias of $\pm 15 \%$ can be expected between different DustTrak units.

In the literature the bias between different DustTrak units was found in the range of $\pm 10 \%$ for the measurements during field campaigns (Wallace et al., 2011). The highest bias between the units was found especially at the lower concentration readings (up to $\pm 40 \%$; Wallace et al., 2011), which is in agreement with our result for the lower concentration range.

\section{Limitations}

DustTrak DRX aerosol monitors were shown to be good alternative to laboratory-grade air quality monitors in terms of cost and portability, and as well optional adjustable calibration factors. However, this technology has as well some drawbacks, which do not consider all aerosol properties. This instrument has to be evaluated in the laboratory and collocated for comparison with a Federal Reference Method (FRM) or Federal Equivalent Method (FEM) in the field campaigns each time a new type of aerosol matrix is introduced. Another limitation of the aerosol monitor might be a lack of sensitivity to particles smaller than 0.1 or larger than $15 \mu \mathrm{m}$, where light-scattering response is no longer sensitive (Chen et al., 2019; Di Biagio et al., 2019). Mass concentrations of high-volatility compounds might be underestimated by the DustTrak DRX due to the nature of aerosol and slow response of the instrument. The last but not least, might be aerosol sampling in terms of improper positioning of the instrument and dilution causing aging, which can affect aerosol mass concentration measurements by the DustTrak DRX aerosol monitor.

\section{CONCLUSIONS}

The DustTrak DRX is a powerful tool for monitoring suspended PM mass concentrations online and a good alternative to the RSP gravimetric method, which is laborintensive and does not allow for real-time tracking of $\mathrm{PM}_{2.5}$ mass concentrations. When measuring Emery oil, the three tested DustTrak units exhibited a linear mass concentration response $\left(\mathrm{R}^{2} \geq 0.9999\right)$ for concentrations from $20 \mu \mathrm{g} \mathrm{m}^{-3}$ to $3 \mathrm{mg} \mathrm{m}^{-3}$ and selectivity for defined sizes, particularly PSL particles in the $\mathrm{PM}_{2.5}$ channel, which is significant in dosimetry.

Simultaneous background measurements established the LOD of the DustTrak as $5 \mu \mathrm{g} \mathrm{m}^{-3}$, which, according to the literature, is typical for light-scattering-based sensors measuring suspended PM (Wallace et al., 2011). The mass concentration sensitivity of the light-scattering methodology is lower than that of the gravimetric method, which generally possesses an LOD of approximately $10 \mathrm{\mu g} \mathrm{m}^{-3}$ (Fierz et al., 2011).

After applying an appropriate PCF (0.38), the ETS measurements from the three DustTrak units tested in this study displayed an acceptable bias $(2-15 \%)$ relative to those obtained via the standard gravimetric method; hence, a maximum bias of $15 \%$ can be expected between different units for the ETS matrix when using a proper PCF.

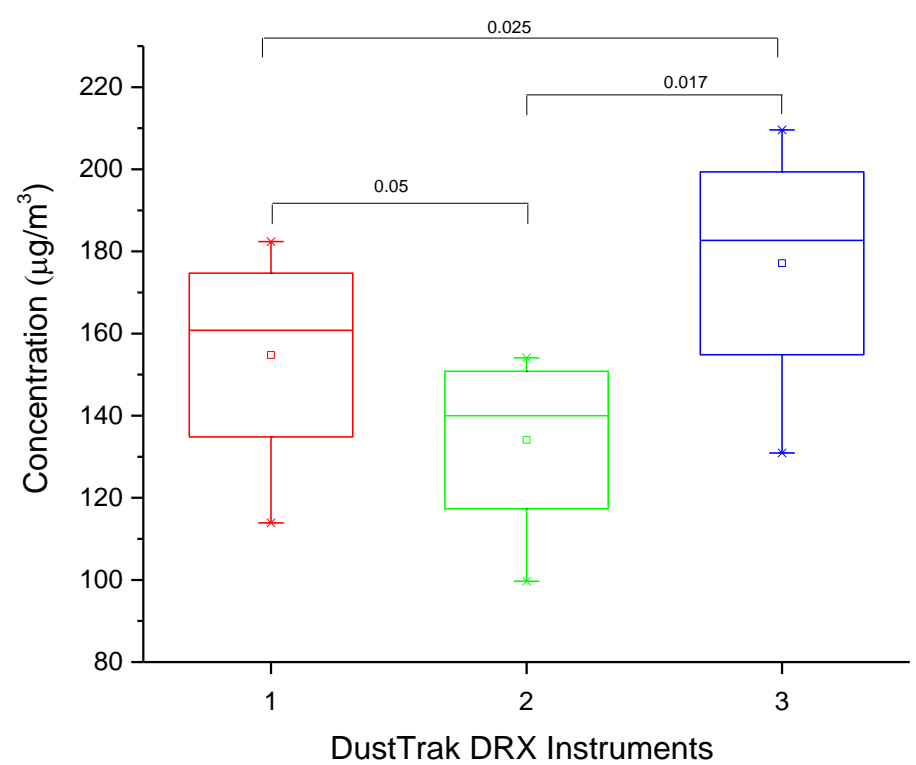

Fig. 5. Comparison of mean concentrations (with SD) of ETS measured by three DustTrak DRX monitors on the PM 2.5 channel in Residential I ventilation conditions $\left(121 \mathrm{~m}^{3} \mathrm{~h}^{-1}\right)$. 
However, one of the tested units (Unit 2) failed validation because of its negative response at very low concentrations (Fig. 2), showing high spread of results in mass concentration linearity (especially for lower concentrations), and high bias (> 15\% relative to the reference method). This performance, which falls outside specifications, may be attributed to the fact that the DustTrak DRX can unexpectedly produce data artefacts in the form of PM concentration spikes (short-lived peaks), as described in the literature (Rivas et al., 2017).

By conducting a rigorous validation, we have demonstrated the suitability of the DustTrak DRX aerosol monitor for measuring particulate matter concentrations and its applicability in indoor air quality studies.

\section{ACKNOWLEDGMENTS}

The authors would like to thank Marceline Robert-Tissot for performing the validation experiments and processing the data, Maria Gomez-Lueso for her assistance with RSP gravimetric analysis, and Maya Mitova for sharing her expertise on indoor air quality regulations.

\section{DISCLAIMER}

Philip Morris International is the sole source of funding and sponsor of this research.

\section{SUPPLEMENTARY MATERIAL}

Supplementary data associated with this article can be found in the online version at https://doi.org/10.4209/aaqr.2 019.11 .0604

\section{REFERENCES}

Allen, G., Sioutas, C., Koutrakis, P., Reiss, R., Lurmann, F.W. and Roberts, P.T. (1997). Evaluation of the TEOM method for measurement of ambient particulate mass in urban areas. J. Air Waste Manage. Assoc. 47: 682-689. https://doi.org/10.1080/10473289.1997.10463923

Amaral, S.S., de Carvalho, J.A., Costa, M.A.M. and Pinheiro, C. (2015). An overview of particulate matter measurement instruments. Atmosphere 6: 1327-1345. https://doi.org/10.3390/atmos6091327

Brasser, L.J., de Koning, H.M. and Schneider, T. (1978). Reference methods and systems for air pollution studies. Stud. Environ. Sci. 2: 7-20. https://doi.org/10.1016/S016 6-1116(08)70807-0

Brook, R.D., Rajagopalan, S., Pope, C.A., Brook, J.R., Bhatnagar, A., Diez-Roux, A.V., Holguin, F., Hong, Y., Luepker, R.V., Mittleman, M.A., Peters, A., Siscovick, D., Smith, S.C., Whitsel, L. and Kaufman, J.D. (2010). Particulate matter air pollution and cardiovascular disease. An update to the scientific statement from the american heart association. Circulation 121: 2331-2378. https://doi.org/10.1161/CIR.0b013e3181dbece1

Brunekreef, B. (2010). Air pollution and human health: From local to global issues. Procedia Soc. Behav. Sci. 2: 6661-6669. https://doi.org/10.1016/j.sbspro.2010.05.010
Buonanno, G., Fuoco, F.C. and Stabile, L. (2011). Influential parameters on particle exposure of pedestrians in urban microenvironments. Atmos. Environ. 45: 14341443. https://doi.org/10.1016/j.atmosenv.2010.12.015

Chen, D., Liu, X., Han, J., Jiang, M., Wang, Z. and Qi, J. (2019). A new angular light scattering measurement of particulate matter mass concentration for homogeneous spherical particles. Sensors 19: 2243. https://doi.org/10.3 390/s19102243

Chung, A., Chang, D.P.Y., Kleeman, M.J., Perry, K.D., Cahill, T.A., Dutcher, D., McDougall, E.M. and Stroud, K. (2001). Comparison of real-time instruments used to monitor airborne particulate matter. J. Air Waste Manage. Assoc. 51: 109-120. https://doi.org/10.1080/10473289.2 001.10464254

Di Biagio, C., Formenti, P., Balkanski, Y., Caponi, L., Cazaunau, M., Pangui, E., Journet, E., Nowak, S., Andreae, M.O., Kandler, K., Saeed, T., Piketh, S., Seibert, D., Williams, E. and Doussin, J.F. (2019). Complex refractive indices and single scattering albedo of global dust aerosols in the shortwave spectrum and relationship to iron content and size. Atmos. Chem. Phys. 19: 1550315531. https://doi.org/10.5194/acp-19-15503-2019

ECS (2006). CEN European Standard EN 15251. Indoor Environmental Input Parameters for Design and Assessment of Energy Performance of Buildings Addressing Indoor Air Quality, Thermal Environment, Lighting and Acoustics. European Committee for Standardization, Brussels.

EEA (2017). Air quality in Europe - 2017 report, EEA (Ed.), 13 Ed, European Environment Agency, pp. 1-76.

EU (2008). Directive 2008/50/EC of the European Parliament and of the Council of 21 May 2008 on ambient air quality and cleaner air for Europe. OJ L 152, 11.6.2008, p. 1-44. http://data.europa.eu/eli/dir/2008/50/oj

Fierz, M., Houle, C., Steigmeier, P. and Burtscher, H. (2011). Design, calibration, and field performance of a miniature diffusion size classifier. Aerosol Sci. Technol. 45: 1-10. https://doi.org/10.1080/02786826.2010.516283

Forster, M., McAughey, J., Prasad, K., Mavropoulou, E. and Proctor, C. (2018). Assessment of tobacco heating product THP1.0. Part 4: Characterisation of indoor air quality and odour. Regul. Toxicol. Pharm. 93: 34-51. https://doi.org/10.1016/j.yrtph.2017.09.017

Friket, J. (1931). The cause of the symptoms found in the Meuse Valley during the fog of December, 1930. Bull. Acad. R. Med. Belg. 11: 683-741.

Grimm, H. and Eatough, D.J. (2009). Aerosol measurement: The use of optical light scattering for the determination of particulate size distribution, and particulate mass, including the semi-volatile fraction. J. Air Waste Manage. Assoc. 59: 101-107. https://doi.org/10.3155/1047-3289.59.1.101

Hinds, W.C. (1999). Aerosol technology: Properties, behavior, and measurements of airborne particles, $2^{\text {nd }} \mathrm{Ed}$. John Willey \& Sons, Inc., United States of America.

Huang, L., Bohac, S.V., Chernyak, S.M. and Batterman, S.A. (2013). Composition and integrity of PAHs, Nitro-PAHs, Hopanes, and Steranes in diesel exhaust particulate matter. Water Air Soil Pollut. 224: 1630. https://doi.org/10.1007/ s11270-013-1630-1 
ISO (1999). ISO/IEC 17025: 1999: General requirements for the competence of testing and calibration laboratories. International Organization for Standardization.

ISO (2001). ISO/IEC 15593:2001: Environmental tobacco smoke - Estimation of its contribution to respirable suspended particles - Determination of particulate matter by ultraviolet absorbance and by fluorescence. International Organization for Standardization.

ISO (2003). ISO/IEC 18144:2003: Environmental tobacco smoke -Estimation of its contribution to respirable suspended particles - Method based on solanesol. International Organization for Standardization.

ISO (2017). ISO/IEC 17025:2017: General requirements for the competence of testing and calibration laboratories. International Organization for Standardization.

Jakobsson, J.K.F., Hedlund, J., Kumlin, J., Wollmer, P. and Londahl, J. (2016). A new method for measuring lung deposition efficiency of airborne nanoparticles in a single breath. Sci. Rep. 6: 36147. https://doi.org/10.1038/srep36 147

Kaufman, P., Dubray, J., Soule, E.K., Cobb, C.O., Zarins, S. and Schwartz, R. (2018). Analysis of secondhand ecigarette aerosol compounds in an indoor setting. Tob. Regul. Sci. 4: 29-37. https://doi.org/10.18001/TRS.4.3.3

Kingham, S., Durand, M., Aberkane, T., Harrison, J., Gaines Wilson, J. and Epton, M. (2006). Winter comparison of TEOM, MiniVol and DustTrak $\mathrm{PM}_{10}$ monitors in a woodsmoke environment. Atmos. Environ. 40: 338-347. https://doi.org/10.1016/j.atmosenv.2005.09.042

Kloog, I., Ridgway, B., Koutrakis, P., Coull, B.A. and Schwartz, J.D. (2013). Long- and short-term exposure to $\mathrm{PM}_{2.5}$ and mortality: Using novel exposure models. Epidemiology 24: 555-561. https://doi.org/10.1097/EDE. 0b013e318294beaa

Kuuluvainen, H., Rönkkö, T., Järvinen, A., Saari, S., Karjalainen, P., Lähde, T., Pirjola, L., Niemi, J.V., Hillamo, R. and Keskinen, J. (2016). Lung deposited surface area size distributions of particulate matter in different urban areas. Atmos. Environ. 136: 105-113. https://doi.org/10.1016/j.atmosenv.2016.04.019

Manibusan, S. and Mainelis, G. (2020). Performance of four consumer-grade air pollution measurement devices in different residences. Aerosol Air Qual. Res. 20: 217-230. https://doi.org/10.4209/aaqr.2019.01.0045

Manikonda, A., Zíková, N., Hopke, P.K. and Ferro, A.R. (2016). Laboratory assessment of low-cost PM monitors. J. Aerosol Sci. 102: 29-40. https://doi.org/10.1016/j.jaer osci.2016.08.010

McGuinn, L.A., Ward-Caviness, C.K., Neas, L.M., Schneider, A., Diaz-Sanchez, D., Cascio, W.E., Kraus, W.E., Hauser, E., Dowdy, E., Haynes, C., Chudnovsky, A., Koutrakis, P. and Devlin, R.B. (2016). Association between satellitebased estimates of long-term $\mathrm{PM}_{2.5}$ exposure and coronary artery disease. Environ. Res. 145: 9-17. https://doi.org/10.1016/j.envres.2015.10.026

McGuinn, L.A., Ward-Caviness, C., Neas, L.M., Schneider, A., Di, Q., Chudnovsky, A., Schwartz, J., Koutrakis, P., Russell, A.G., Garcia, V., Kraus, W.E., Hauser, E.R., Cascio, W., Diaz-Sanchez, D. and Devlin, R.B. (2017). Fine particulate matter and cardiovascular disease: Comparison of assessment methods for long-term exposure. Environ. Res. 159: 16-23. https://doi.org/10.1016/j.envres.2017.0 7.041

McMullen, T.B., Faoro, R.B. and Morgan, G.B. (1970). Profile of pollutant fractions in nonurban suspended particulate matter. J. Air Pollut. Control Assoc. 20: 369372. https://doi.org/10.1080/00022470.1970.10469414

McMurry, P.H. (2000). A review of atmospheric aerosol measurements. Atmos. Environ. 34: 1959-1999. https://doi.org/10.1016/S1352-2310(99)00455-0

McNamara, M.L., Noonan, C.W. and Ward, T.J. (2011). Correction factor for continuous monitoring of wood smoke fine particulate matter. Aerosol Air Qual. Res. 11: 315-322. https://doi.org/10.4209/aaqr.2010.08.0072

Mehadi, A., Moosmüller, H., Campbell, D.E., Ham, W., Schweizer, D., Tarnay, L. and Hunter, J. (2020). Laboratory and field evaluation of real-time and near realtime $\mathrm{PM}_{2.5}$ smoke monitors. J. Air Waste Manage. Assoc. 70: 158-179. https://doi.org/10.1080/10962247.2019.16 54036

Meišutovič-Akhtarieva, M., Prasauskas, T., Čiužas, D., Krugly, E., Keraitytė, K., Martuzevičius, D. and Kauneliené, V. (2019). Impacts of exhaled aerosol from the usage of the tobacco heating system to indoor air quality: A chamber study. Chemosphere 223: 474-482. https://doi.org/10.1016/j.chemosphere.2019.02.095

Melstrom, P., Koszowski, B., Thanner, M.H., Hoh, E., King, B., Bunnell, R. and McAfee, T. (2017). Measuring $\mathrm{PM}_{2.5}$, ultrafine particles, nicotine air and wipe samples following the use of electronic cigarettes. Nicotine Tob. Res. 19: 1055-1061. https://doi.org/10.1093/ntr/ntx058

METAS (2017). Calibration of dust monitors. https://w ww.metas.ch/dam/metas/de/data/Fachbereiche/PartikelA erosole/calibration-of-dust-monitors.pdf

Methner, M., Hodson, L. and Geraci, C. (2010). Nanoparticle Emission Assessment Technique (NEAT) for the identification and measurement of potential inhalation exposure to engineered nanomaterials - part A. J Occup Environ Hyg. 7: 127-132. https://doi.org/10.108 0/15459620903476355

Mitova, M.I., Campelos, P.B., Goujon-Ginglinger, C.G., Maeder, S., Mottier, N., Rouget, E.G.R., Tharin, M. and Tricker, A.R. (2016). Comparison of the impact of the Tobacco Heating System 2.2 and a cigarette on indoor air quality. Regul. Toxicol. Pharmacol. 80: 91-101. https://doi.org/10.1016/j.yrtph.2016.06.005

Mitova, M.I., Bielik, N., Campelos, P.B., Cluse, C., GoujonGinglinger, C.G., Jaquier, A., Gomez Lueso, M., Maeder, S., Pitton, C., Poget, L., Polier-Calame, J., Rotach, M., Rouget, E.G.R., Schaller, M., Tharin, M. and Zaugg, V. (2019). Air quality assessment of the Tobacco Heating System 2.2 under simulated residential conditions. Air Qual. Atmos. Health 12: 807-823. https://doi.org/10.100 7/s11869-019-00697-6

Muylle, E., Hachez, D. and Verduyn, G. (1978). An evaluation of measuring methods for particulate matter. Stud. Environ. Sci. 2: 113-125. https://doi.org/10.1016/S 0166-1116(08)70819-7 
Nousiainen, T. (2009). Optical modeling of mineral dust particles: A review. J. Quant. Spectrosc. Radiat. Transfer. 110: 1261-1279. https://doi.org/10.1016/j.jqsrt.2009.03. 002

Ott, W.R. and Siegmann, H.C. (2006). Using multiple continuous fine particle monitors to characterize tobacco, incense, candle, cooking, wood burning, and vehicular sources in indoor, outdoor, and in-transit settings. Atmos. Environ. 40: 821-843. https://doi.org/10.1016/j.atmosen v.2005.08.020

Pope, C.A. and Dockery, D.W. (2006). Health Effects of Fine Particulate Air Pollution: Lines that Connect. J. Air Waste Manage. Assoc. 56: 709-742. https://doi.org/10.10 80/10473289.2006.10464485

Protano, C., Avino, P., Manigrasso, M., Vivaldi, V., Perna, F., Valeriani, F. and Vitali, M. (2018). Environmental electronic vape exposure from four different generations of electronic cigarettes: airborne particulate matter levels. Int. J. Environ. Res. Public Health 15: 2172. https://doi.org/10.3390/ijerph15102172

Protano, C., Manigrasso, M., Cammalleri, V., Biondi Zoccai, G., Frati, G., Avino, P. and Vitali, M. (2020). Impact of electronic alternatives to tobacco cigarettes on indoor air particular matter levels. Int. J. Environ. Res. Public Health. 17: 2947. https://doi.org/10.3390/ijerph17082947

Pui, D.Y.H. (1996). Direct-reading instrumentation for workplace aerosol measurements. A review. Analyst 121: 1215-1224. https://doi.org/10.1039/AN9962101215

Rakowska, A., Wong, K.C., Townsend, T., Chan, K.L., Westerdahl, D., Ng, S., Močnik, G., Drinovec, L. and Ning, Z. (2014). Impact of traffic volume and composition on the air quality and pedestrian exposure in urban street canyon. Atmos. Environ. 98: 260-270. https://doi.org/10. 1016/j.atmosenv.2014.08.073

Ramachandran, G., Adgate, J.L., Hill, N., Sexton, K., Pratt, G.C. and Bock, D. (2000). Comparison of short-term variations (15-minute averages) in outdoor and indoor $\mathrm{PM}_{2.5}$ concentrations. J. Air Waste Manage. Assoc. 50: 1157-1166. https://doi.org/10.1080/10473289.2000.104 64160

Rissler, J., Gudmundsson, A., Nicklasson, H., Swietlicki, E., Wollmer, P. and Londahl, J. (2017). Deposition efficiency of inhaled particles $(15-5000 \mathrm{~nm})$ related to breathing pattern and lung function: an experimental study in healthy children and adults. Part. Fibre Toxicol. 14: 10. https://doi.org/10.1186/s12989-017-0190-8

Rivas, I., Mazaheri, M., Viana, M., Moreno, T., Clifford, S., He, C., Bischof, O.F., Martins, V., Reche, C., Alastuey, A., Alvarez-Pedrerol, M., Sunyer, J., Morawska, L. and Querol, X. (2017). Identification of technical problems affecting performance of DustTrak DRX aerosol monitors. Sci. Total Environ. 584-585: 849-855. https://doi.org/10. 1016/j.scitotenv.2017.01.129

Ruprecht, A.A., De Marco, C., Saffari, A., Pozzi, P., Mazza, R., Veronese, C., Angellotti, G., Munarini, E., Ogliari, A.C., Westerdahl, D., Hasheminassab, S., Shafer, M.M., Schauer, J.J., Repace, J., Sioutas, C. and Boffi, R. (2017). Environmental pollution and emission factors of electronic cigarettes, heat-not-burn tobacco products, and conventional cigarettes. Aerosol Sci. Technol. 51: 674684. https://doi.org/10.1080/02786826.2017.1300231

Sajjadi, S.A., Zolfaghari, G., Adab, H., Allahabadi, A. and Delsouz, M. (2017). Measurement and modeling of particulate matter concentrations: Applying spatial analysis and regression techniques to assess air quality. Methods $X$ 4: 372-390. https://doi.org/10.1016/j.mex.2017.09.006

Segersson, D., Eneroth, K., Gidhagen, L., Johansson, C., Omstedt, G., Nylén, A.E. and Forsberg, B. (2017). Health impact of $\mathrm{PM}_{10}, \mathrm{PM}_{2.5}$ and black carbon exposure due to different source sectors in Stockholm, Gothenburg and Umea, Sweden. Int. J. Environ. Res. Public Health 14: 742. https://doi.org/10.3390/ijerph14070742

Silva, R.A., West, J.J., Zhang, Y., Anenberg, S.C., Lamarque, J.F., Shindell, D.T., Collins, W.J., Dalsoren, S., Faluvegi, G., Folberth, G., Horowitz, L.W., Nagashima, T., Naik, V., Rumbold, S., Skeie, R., Sudo, K., Takemura, T., Bergmann, D., Cameron-Smith, P., ... Zeng, G. (2013). Global premature mortality due to anthropogenic outdoor air pollution and the contribution of past climate change. Environ. Res. Lett. 8: 034005. https://doi.org/10.1088/17 48-9326/8/3/034005

Singer, B.C. and Delp, W.W. (2018). Response of consumer and research grade indoor air quality monitors to residential sources of fine particles. Indoor Air 28: 624639. https://doi.org/10.1111/ina.12463

Soule, E.K., Maloney, S.F., Spindle, T.R., Rudy, A.K., Hiler, M.M. and Cobb, C.O. (2017). Electronic cigarette use and indoor air quality in a natural setting. Tob. Control. 26: 109-112. https://doi.org/10.1136/tobaccocontrol-2015052772

Sousan, S., Koehler, K., Hallett, L. and Peters, T.M. (2017). Evaluation of consumer monitors to measure particulate matter. J. Aerosol Sci. 107: 123-133. https://doi.org/10.1 016/j.jaerosci.2017.02.013

Sousan, S., Koehler, K., Thomas, G., Park, J.H., Hillman, M., Halterman, A. and Peters, T.M. (2016). Intercomparison of low-cost sensors for measuring the mass concentration of occupational aerosols. Aerosol Sci. Technol. 50: 462-473. https://doi.org/10.1080/02786826 .2016 .1162901

TSI (2013). Rationale for programming a photometer calibration factor (PCF) of 0.38 for ambient monitoring. TSI Inc. Application Note.

TSI (2017). Operation and service manual, DustTrak DRX aerosol monitor. Revision E, P/N 6008408, TSI Incorporated, Shoreview, MN.

U.S. EPA (1997). National Primary and Secondary Ambient Air Quality Standards, 40 Code of US Federal Regulation, Chapter 1, Part 50.

van Dinther, D., Blom, M., Weijers, E., Elst, E., Vercauteren, J., Stroobants, C. and Peeters, O. (2019). Testing of eight particulate matter sensors in the lab, 21st EGU General Assembly, EGU2019, Proceedings from the conference held 7-12 April, Vienna, Austria, id.15296

Volesky, K.D., Maki, A., Scherf, C., Watson, L., Van Ryswyk, K., Fraser, B., Weichenthal, S.A., Cassol, E. and Villeneuve, P.J. (2018). The influence of three e-cigarette models on indoor fine and ultrafine particulate matter 
concentrations under real-world conditions. Environ. Pollut. 243: 882-889. https://doi.org/10.1016/j.envpol.2 018.08.069

Wallace, L.A., Wheeler, A.J., Kearney, J., Van Ryswyk, K., You, H., Kulka, R.H., Rasmussen, P.E., Brook, J.R. and $\mathrm{Xu}, \mathrm{X}$. (2011). Validation of continuous particle monitors for personal, indoor, and outdoor exposures. J. Exposure Sci. Environ. Epidemiol. 21: 49-64. https://doi.org/10.10 38/jes.2010.15

Wang, X., Chancellor, G., Evenstad, J., Farnsworth, J.E., Hase, A., Olson, G.M., Sreenath, A. and Agarwal, J.K. (2009). A novel optical instrument for estimating size segregated aerosol mass concentration in real time. Aerosol Sci. Technol. 43: 939-950. https://doi.org/10.10 80/02786820903045141

Wang, Z., Calderón, L., Patton, A.P., Allacci, M.S., Senick, J., Wener, R., Andrews, C.J. and Mainelis, G. (2016). Comparison of real-time instruments and gravimetric method when measuring particulate matter in a residential building. J. Air Waste Manage. Assoc. 66: 1109-1120. https://doi.org/10.1080/10962247.2016.1201022

WHO (2006). Air quality guidelines: Global update 2005. Particulate matter, ozone, nitrogen dioxide and sulfur dioxide. World Health Organization Regional Office for Europe, Copenhagen.
WHO (2013). Review of evidence on health aspects of air pollution - REVIHAAP project. Technical report., pp. 1302. World Health Organization.

Wong-Parodi, G., Dias, M.B. and Taylor, M. (2018). Effect of using an indoor air quality sensor on perceptions of and behaviors toward air pollution (Pittsburgh Empowerment Library Study): Online survey and interviews. JMIR mHealth uHealth. 6: e48-e48. https://doi.org/10.2196/mh ealth. 8273

Zhang, J., Marto, J.P. and Schwab, J.J. (2018). Exploring the applicability and limitations of selected optical scattering instruments for PM mass measurement. Atmos. Meas. Tech. 11: 2995-3005. https://doi.org/10.5194/amt-112995-2018

Zhao, B., Johnston, F.H., Salimi, F., Kurabayashi, M. and Negishi, K. (2020). Short-term exposure to ambient fine particulate matter and out-of-hospital cardiac arrest: A nationwide case-crossover study in Japan. Lancet Planet. Health 4: e15-e23. https://doi.org/10.1016/S25425196(19)30262-1

Received for review, November 27, 2020

Revised, July 3, 2020

Accepted, July 20, 2020 